\title{
Análisis iconográfico: Sacrificio humano de José Clemente Orozco
}

\author{
Iconographic Analysis: Human Sacrifice of José Clemente Orozco
}

\author{
Jesús Adrián Hernández Luna ${ }^{a}$
}

\begin{abstract}
:
This article is focused on the research on the work "Human Sacrifice" by José Clemente Orozco. The objectives of this research are: to analyze diverse sources, both ethnohistorical and contemporary, to distinguish the different artistic influences in Orozco's work, to analyze the work with the iconographic method and to understand what that the work Human Sacrifice seeks to transmit to viewers.

Orozco is the result of his time. The period in which he lived was plagued by warfare, nationalism and uncertainty. The work Human Sacrifice seeks to question the era and the idea of war, in his work he confronts us and tells us that despite the great advances of humanity we continue to kill ourselves.
\end{abstract}

\section{Keywords:}

Muralism, José Clemente Orozco, Teules, Human Sacrifice.

\section{Resumen:}

Este artículo se centra en la investigación sobre la obra "Sacrificio humano" de José Clemente Orozco, cuyos objetivos son: analizar diversas fuentes tanto etnohistóricas como contemporáneas, distinguir las diversas influencias artísticas en la obra de Orozco, analizar la obra con el método iconográfico y comprender lo que la obra Sacrificio Humano busca transmitir a los espectadores.

Orozco es resultado de su época, el periodo en el que vivió estuvo plagado de conflictos bélicos, nacionalismos e incertidumbre. La obra Sacrificio humano busca cuestionar la época y la idea de la guerra, en su obra nos confronta y nos dice que a pesar de los grandes avances de la humanidad seguimos matándonos.

\section{Palabras Clave:}

Muralismo, José Clemente Orozco, Teules, Sacrificio Humano.

\section{Introducción}

Este artículo se centra en los resultados de una investigación sobre la obra titulada Sacrificio humano, realizada por José Clemente Orozco durante el año de 1947, la cual pertenece a la colección del Museo de Arte Alvar y Carmen T. de Carrillo Gil. Esta obra es un óleo sobre tela de $194 \times 122 \mathrm{~cm}$. El objetivo de la investigación es comprender lo que la obra Sacrificio humano busca transmitir a los espectadores, para lo cual se han consultado diversas fuentes que permiten establecer el contexto histórico de ésta, distinguiendo las diversas influencias artísticas en la obra de Orozco. Para realizar el análisis específico del cuadro se recurrió al método iconográfico. Con todo ello, se pretende explicar la obra Sacrificio humano, su relación con el muralismo mexicano, la exposición Los Teules y la idea que ofrece Orozco acerca de la guerra.

El contexto histórico de la obra se ubica dentro de la tercera etapa del movimiento muralista mexicano. Orozco no sólo pintaba murales, también se dedicó a la pintura de caballete, en esta última se ubica la obra Sacrificio humano. En lo que respecta al muralismo, fue un movimiento artístico que comenzó en 1921. El grupo de artistas que conformaba este movimiento tenía por objetivo consolidar los ideales revolucionarios y consumar la idea de la mexicanidad dentro de la sociedad; principalmente buscaron implementar ideas nacionalistas en la sociedad con sus obras. Para ello, realizaron diversos murales en zonas públicas que estaban al acceso de toda la población. A través de

\footnotetext{
a Autor de Correspondencia, Universidad Autónoma del Estado de Hidalgo, México ORCID: https://orcid.org/0000-0001-6991-9806 Email: he352647@uaeh.edu.mx
} 
estos murales, los artistas representaron tanto las ideas del movimiento como sus propios ideales.

Este movimiento se dividió en tres etapas y en cada una de ellas, los ideales y representaciones del movimiento fueron evolucionando. Dentro del movimiento destacaron tres personajes, conocidos como los iniciadores: David Alfaro Siqueiros, Diego Rivera y José Clemente Orozco. También, hubo otros muralistas que destacaron como: Jorge González Camarena, Aurora Reyes y Carlos Mérida. Todos estos artistas se caracterizaron por la voluntad de crear un arte independiente y al alcance de todos. Este movimiento se caracterizó por crear un arte nacional, además de consolidar ideales nacionalistas con sus obras.

José Clemente Orozco fue un muralista y pintor originario del estado de Jalisco, se inició como caricaturista y, de manera posterior, comenzó a realizar pintura mural. Dentro del movimiento muralista mexicano, no solo fue uno de los precursores, sino a su vez fue uno de los pintores más importantes y reconocidos. Su obra Sacrificio humano, es una de las más trascendentes, ya que los temas del pasado indígena son recurrentes tanto en sus obras como en el movimiento.

Esta pintura representa uno de los rituales más comunes e importantes del pasado indígena, por lo que es necesario también, entender que su obra se encuentra inmersa en la exposición Los Teules. Esta exposición conjunta diversas pinturas que siguen una misma línea temática, la cual es la conquista de México, con base en la obra Historia verdadera de la conquista de la Nueva España de Bernal Díaz del Castillo. Cabe destacar que Orozco tuvo una estancia en el Colegio Nacional, y fue ahí donde desarrolló mucha inspiración para sus obras pertenecientes a esta exposición.

El siglo XX estuvo lleno de conflictos militares, la revolución mexicana, la guerra civil española, la primera y segunda guerra mundial son solo algunos ejemplos de los conflictos dados en esa época. La exposición Los Teules es una crítica a la guerra, y sus consecuencias, a su vez, el autor busca retratar la crudeza de la conquista de México. En esta exposición se confronta al espectador y a la humanidad entera. El pintor nos cuestiona de manera directa, preguntándonos: ¿por qué somos participes de este tipo de actos? ¿Por qué, a pesar de encontrarse en pleno siglo $X X$, el hombre se sigue matando el uno al otro?

En la exposición podemos identificar esta crítica, sobre todo, en obras como Los Teules IV, El desmembrado y Sacrificio humano. En ellas podemos conocer la visión que el autor tenía de la guerra, remontándose a uno de los acontecimientos más importantes en la historia de México, la conquista de Tenochtitlan. Con este trabajo de investigación se pretende entender una faceta más del autor, además de analizar todo aquello que comprende la obra, y poder explicar lo que Orozco buscaba transmitir.

Esta investigación fue realizada por la importancia que tiene este autor para el arte mexicano, además de identificar que han sido escasos los análisis que se han hecho a esta obra en particular. El trabajo aporta nueva información acerca de la obra Sacrificio humano de Orozco, la cual es relevante para poder entender la exposición Los Teules, y comprender a su vez, esta faceta del autor.

La información del artículo se presenta en cuatro partes. Para comenzar, abordaremos el tema del muralismo en México, en el que se exponen los ideales del movimiento y las principales temáticas que lo caracterizan. En el segundo apartado, nos acercaremos a la vida de Orozco, y a la exposición Los Teules. En este apartado conoceremos su vida artística y un poco de la inspiración de una de sus exposiciones más importantes. Después, en el tercero, me centro en la principal fuente de inspiración de la exposición Los Teules y su obra Sacrificio humano, así como, en su relación con la obra de Bernal Díaz del Castillo. Esto para dar paso a la descripción de la obra desde la perspectiva iconográfica, finalmente, se presentan algunas consideraciones.

\section{El muralismo en México}

El muralismo fue un movimiento artístico iniciado en México a principios del siglo $\mathrm{XX}$, el movimiento tenía como objetivo configurar la conciencia nacional $y$ construir una memoria colectiva, para generar una idea de nación. "Después de la Revolución de 1910, se impuso en México la necesidad modernizar el país y de construir una identidad cultural nacional" (Mandel, 2007: 38). En este mismo año, se planteó la iniciativa para que artistas mexicanos pudieran realizar sus obras en edificios públicos, a pesar de esto, fue hasta 1921 cuando comenzó formalmente el movimiento muralista mexicano.

José Vasconcelos, uno de los principales intelectuales mexicanos, asumió funciones como secretario de educación pública en el gobierno del presidente Álvaro Obregón, quien comisionó a distintos artistas a pintar una serie de murales en las paredes de la Escuela

Nacional Preparatoria (Delgadillo y Rico, 2008).

Durante este período, Vasconcelos definió el primer programa cultural del Estado Postrevolucionario, el cual marcaba pautas legales, administrativas, institucionales e ideológicas de los sucesivos gobiernos. Su plan educativo se inspiró en propuestas de revolucionarios soviéticos, tales como, Anatoli Lunachersky y Máximo Gorki, quienes impulsaron el desarrollo de un arte público y más del $20 \%$ del presupuesto nacional se destinó a la educación y a la cultura (Mandel, 2007).

Vasconcelos buscó retomar la iniciativa norteamericana de campañas de alfabetización y de bibliotecas públicas. 
Su principal discurso se abocó a su proyecto de educación popular y la modernización del país, mediante el arte y la cultura. Conforme el Estado ampliaba su plan educativo, multiplicando el número de escuelas, estas se convirtieron en centro de difusión de una nueva concepción de la realidad: la ideología de la Revolución Mexicana. El nacionalismo, como parte integral de dicha ideología, respondió a afianzar la unidad nacional: un espacio ideológico que lograra disolver las diferencias sociales. Vasconcelos, nombrado por Obregón secretario del Ministerio de Educación Pública en 1920, sostiene que el concepto clave de la revolución es la enseñanza que puede, mediante un plan educativo nacionalista, limar los conflictos entre los mexicanos, produciendo la homogenización de todos los habitantes (Mandel, 2007).

De esta manera, la cultura adquirió un carácter integrador. El primer paso fue la incorporación del indio a la "civilización", tomando el idioma español como medio de unificación nacional. Lo que se buscaba es una unificación cultural en el país. El fenómeno del muralismo está sumamente ligado a todo esto, pues el proyecto cultural, realizaría una imagen de la revolución obrera y campesina, buscaba un arte consagratorio para legitimar a la nación y gestar un sentimiento de unión entre el pueblo.

Con el tiempo, la escuela muralista mexicana comenzó a obtener prestigio internacional, no solo por ser una corriente artística, sino también por ser un movimiento social y político de resistencia e identidad. Los muralistas retrataron temas como la revolución, la lucha de clases y al hombre indígena. Entre sus miembros, destacaron David Alfaro Siqueiros, José Clemente Orozco, Diego Rivera, conocidos como los tres grandes de la pintura mural mexicana. Además de ellos, también otros muralistas tuvieron relevancia, como Jean Charlot, Pablo O'Higgins, Juan O' Gorman y Jorge González Camarena. Según Ocampo, "Vasconcelos estimuló las artes plásticas; inicio el desarrollo de la pintura mural en México, con tendencia hacia un Nacionalismo Cultural artístico" (Ocampo, 2005:149).

Durante la década de los 20s, los murales pintados por Rivera, Orozco y Siqueiros se dividen en dos grupos: el primero es constituido por obras ordenadas por Vasconcelos, y terminadas antes de finalizar su gestión en la Secretaria de Educación Pública, en 1924. Estos murales reflejan el marco ideológico y estético que buscaba Vasconcelos. El segundo grupo son, también, obras encargadas por Vasconcelos y realizadas durante su gestión, con un marco estilístico y temas que se apartan de esa visión; se aproximan a un arte político, didáctico y populista, con el que se suele asociar al movimiento muralista mexicano (Mandel, 2007).

Los temas relacionados con el México antiguo tuvieron mucha relevancia para los muralistas.
La valoración de la cultura prehispánica, fue fundamental para la conformación de la identidad nacional, provino del aporte de la antropología y la arqueología mexicanas, así como también fue decisivo el descubrimiento del arte europeo primitivo. En este proceso de configurar la propia identidad, el muralismo recupera las tradiciones populares, las llamadas artes menores y el pasado prehispánico (Mandel, 2007:40-41). El muralismo se suele dividir en tres etapas: la primera, abarca de 1921 a 1934. Durante esta etapa predominan temas relacionados con la revolución mexicana, los problemas sociales, la reivindicación del pasado indígena, las injusticias sociales, entre otros. La segunda, es referida partir de 1934 a 1940; esta es una etapa de reflexión, los temas se mantienen, pero los artistas comienzan a debatir el camino que debe tomar el movimiento. Finalmente, en la tercera etapa, algunos artistas comenzaron a omitir los temas de la revolución para dar paso a temas más generales (Museo del Palacio de Bellas Artes, 2016).

El muralismo fue esencial para unificar al país, debido a que se estaba recuperando de una revolución, se necesitaban considerar los ideales forjados durante el movimiento armado y buscar afianzarlos en la población.

El sello distintivo del movimiento es un marcado nacionalismo, un deseo de tener identidad nacional, la búsqueda de lo que la generación precedente a los muralistas llamó el alma nacional y que a partir de la época que nos ocupa llamamos lo mexicano. Dicha búsqueda explica algunas de las fuentes que nutren al muralismo mexicano, como es el arte prehispánico, dado que es la única expresión artística realmente autónoma, creada antes de que América entrara en contacto con Europa. Es así, que el arte popular mexicano, producido por y para el pueblo, libre de afectación y de academia, es verdaderamente autóctono (Garrido, 2009).

Este movimiento se caracterizó por tener un fin educativo. Asimismo, los artistas de la época tuvieron gran influencia de las ideas marxistas, y a través de los murales proyectaron la situación social y política de México.

Se considera que el movimiento artístico del muralismo mexicano ha jugado un papel central en la construcción de la historia y la identidad nacional en el periodo posrevolucionario; las obras de este movimiento expresan el ideal de nación, emanado del movimiento armado que inició en 1910 (Delgadillo y Rico, 2008: 6).

A su vez, los muralistas se convirtieron en cronistas de la historia mexicana y del sentimiento nacionalista. "El muralismo surgió para construir una visión legitimadora del Estado revolucionario y para construir una identidad homogénea de lo mexicano" (Delgadillo y Rico, 2008: 6). Los muralistas no solo cumplieron la función de legitimar el estado-nación, a través de sus murales, también tuvieron rechazo hacía el arte estilista y burgués 
exaltando, en oposición a este, un arte de índole monumental y público.

Los pintores muralistas proponen un arte público monumental al servicio de la Revolución Mexicana que expresa un fuerte compromiso social, cuyo antecedente moral y ético era Guadalupe Posada y que tanto Rivera como David Alfaro Siqueiros pretendían encarnar. La apertura propiciada por el Estado brindó el marco institucional para la elaboración del proyecto muralista mexicano. La joven república, luego de la revolución, necesitaba un arte grandioso, capaz de conmover e impresionar a las multitudes. El fresco, practicado ya por las culturas precolombinas y estudiado por los dos muralistas -Rivera y Siqueiros- en Italia, pareció la técnica por excelencia (Mandel, 2007).

\section{José Clemente Orozco}

Nació en la Ciudad Guzmán, también conocida como Zapotlán el Grande, Jalisco, el 22 de noviembre de 1883. Su infancia la pasó en Guadalajara y Ciudad de México. Al llegar a la ciudad de México, en 1890, se sintió sumamente atraído por la obra de José Guadalupe Posada y puesto que su familia no quería que estudiase arte, estuvo tres años en la Escuela de Peritos Agrícolas, en donde aprendió a dibujar mapas. Debido a su gran talento poco a poco fue progresando y convirtiéndose en más que un dibujante.

La obra más temprana de Orozco muestra una clara influencia de Julio Ruelas y el Dr. Atl. Para 1912 comenzó a hacer una serie de dibujos de chulos y prostitutas. Orozco también se dedicó a ser caricaturista, haciendo dibujos para los periódicos, esto le permitía ganarse la vida. Posteriormente, emigró a los Estados Unidos, trabajando como pintor de rótulos y después, en una fábrica de muñecas (Lucie-Smith, 1993). Finalmente, en 1920, regreso a México y se incorporó al movimiento muralista, el cual estaba prosperando con gran rapidez.

A su llegada, Vasconcelos lo puso a trabajar junto a Rivera en la Escuela Nacional Preparatoria, en donde tuvo obras muy destacadas. Los primeros murales que realizó, reflejaban, en gran parte, su experiencia como caricaturista, lo cual causó polémicas, por su postura política.

En junio de 1924 se amotinaron algunos grupos de estudiantes conservadores. Orozco fue despedido y algunas de sus pinturas mutiladas. No obstante, dos años después se le permitió continuar (Lucie-Smith, 1993: 215).

En 1927 volvió a ir a los Estados Unidos, y estuvo allí hasta 1934. Pintó murales en el Pomona Collage, California, en la New School for Social Reseach de Nueva York y en el Darttmouth College de New Hampshire. Durante ese mismo año, visitó Europa, lo cual le permitió ver obras que solo conocía por descripciones e ilustraciones.
A pesar de su repetidamente expresado recelo de la influencia europea, éstas le provocaron una gran impresión, en especial la escala y la fuerza de los frescos de Miguel Ángel en la Capilla Sextina y la intensidad de las pinturas del Greco en Toledo (LucieSmith, 1993: 216).

La obra de Orozco no solo fue influida por las artes europeas, sino también por exposiciones que visitó en Estados Unidos y en gran medida, por el mismo arte de sus contemporáneos mexicanos. Todo esto le ayudó a forjar su propio estilo pictórico. Una de las principales influencias, en su obra fue el expresionismo, el cual, a mi parecer, se vio reflejado principalmente en su obra más tardía, en concreto, en su exposición Los Teules, dentro de la que destacan las obras: el Sacrificio Humano y Teules IV.

Nuevamente, en 1936, regresó a México, por invitación de Everardo Topete, gobernador del estado de Jalisco. Al regresar pintó una serie de murales en su Guadalajara natal, tanto en la sala de actos de la universidad como en el Palacio de Gobierno. También creó un gran círculo de composiciones para la iglesia cerrada al culto del Hospicio Cabañas. De acuerdo con Lucie-Smith, se puede afirmar que "El mensaje de los murales no es consolador: el mundo indio está percibido como cruel y salvaje, y la conquista española como aún más atroz". (Lucie-Smith, 1993: 216).

Este punto resulta de interés, pues si comparamos a Orozco con Rivera, la representación del pasado indígena, es totalmente diferente. Mientras que Orozco muestra la crueldad de los actos españoles, la matanza y la guerra, Rivera hace representaciones totalmente distintas centrándose en tópicos como la vida común, tradiciones, etcétera. A diferencia de Rivera, Orozco no buscó que sus murales fueran un medio de reivindicación, sino que muchas veces buscó, con ellos, hacer una crítica o mostrar la realidad desde su punto de vista. Un claro ejemplo de ello, es la exposición de Los Teules, en donde podemos ver la perspectiva que tuvieron los nativos al ser conquistados por los españoles.

Asimismo, Orozco fue uno de los muralistas que más se distanció del grupo, pues su obra tenía una gran variedad de temas afines y no solía concentrarse en algún tema en concreto. Si bien tuvo intereses políticos en su obra, no tuvo intereses partidistas,

...mantuvo siempre una actitud crítica, la que no le permitió afiliarse a ningún partido político ni participar del entusiasmo generalizado por el indigenismo, el socialismo, el progreso y mucho menos por la Revolución (Garrido, 2009: 63).

A pesar de ello, sí compartía la convicción más importante del movimiento, que era pintar murales en zonas públicas, para hacer su arte accesible a toda la ciudadanía. Claro que este no fue el único tipo de pintura 
que realizó, debemos entender que Orozco tuvo una producción multifacética, y gran parte de su obra, también fueron obras de caballete.

Orozco buscaba con sus murales representar una idea, es decir, el tema solamente era un medio y no un fin. De acuerdo con Esperanza Garrido, para este muralista, "detrás de un mural, de hecho, de toda verdadera obra de arte, lo que hay no es un cuento sino una idea." (Garrido, 2009:63). Orozco creía que la pintura mural requería un gran valor, pues era pensar en voz alta. Asimismo, Orozco contaba con un gran sentido crítico, y siempre mantuvo una postura americanista en su arte:

...con orgullo proclamaba su ser americano, y si

América era el nuevo continente, debía procurar un arte nuevo, un arte americano, cosa que es un logro indiscutible del Muralismo Mexicano (Garrido, 2009: 67). Dentro de la obra de Orozco, se puede notar que los murales tienen un cierto contenido histórico y muchas veces, sus personajes tienen algo de atemporal y universal: "Para ello evita pintar rostros, uniformes o banderas reconocibles, podemos identificar al militar, a la víctima, al pueblo" (Garrido, 2009: 68). Todos son anónimos, a mi parecer, Orozco hace esto para que cada persona al ver alguna de sus pinturas se pueda identificar como parte de ella. Es decir, no hay ningún personaje en concreto, no hay nombres o rostros, por ende, el personaje de la pintura puedo ser yo o puedes ser tú.

Su estilo pictórico está fundado en un realismo de carácter expresionista, conscientemente ligado a las viejas tradiciones artísticas mexicanas, de violento dinamismo y amplísima factura. El afán de lograr en sus cuadros recios efectos emotivos dio a sus obras simplicidad de línea y color y audacia en la interpretación de motivos contemporáneos y valores sociales.

La obra de Orozco está sumamente arraigada a la escuela mexicana de pintura, pero como ya he mencionado, debido al contacto que tuvo con arte del extranjero (Estados Unidos y Europa), pudo crear obras que tuvieron influencias de distintos artistas y distintas corrientes artísticas. En este sentido, considero que la mayor influencia que tiene su obra Sacrificio Humano es el expresionismo. Si bien el expresionismo, es un movimiento que influenció a los tres muralistas, Orozco es su referente último.

Como ya se mencionó, José Clemente Orozco empezó como caricaturista y es el más cercano a la obra de Guadalupe Posada. En La Trinchera 18, las formas puntiagudas de las figuras recuerdan a las de los expresionistas alemanes, Kirchner y Heckel. Sin embargo, pese a que siempre estuvo presente en su obra la expresión precisa de la caricatura, no puede desconocerse otra faceta en su arte, en la que nos encontramos con imágenes de tal complejidad, que para ser descifradas, se requieren del conocimiento del iniciado. Es así, porque son imágenes organizadas en alegorías simbólicas que remiten a un código (Mandel, 2007).

En términos generales, el expresionismo fue un movimiento artístico y cultural nacido en Alemania, a finales del siglo XIX y principios del XX. Sus mayores exponentes, E.L. Kirchner, Erich Heckel, Karl SchmidtRottluff, Max Pechstein y Otto Mueller, fueron quienes le dieron gran auge al arte gráfico de esta corriente, formaron en Dresde un grupo al que llamaron el Brucke. Estilo que se fue expandiendo por Europa, tras algunos años (Consejo Alemán de Arte, 1967)

Esta corriente promueve la supremacía de la expresión por sobre la descripción, es decir la obra se centra en la expresividad. A su vez, surgió como reacción al impresionismo, frente al naturalismo y el carácter positivista de este movimiento de finales del siglo XIX. Los expresionistas defendían un arte más personal e intuitivo, donde predominara la visión interior del artista (expresión) frente a la plasmación de la realidad (impresión).

El expresionismo también tuvo otras características, entre las que se destacan:

1. Busca plasmar una deformación de la realidad presentándola de forma más subjetiva.

2. La angustia existencial es el principal motor de su estética.

3. Pretenden potenciar las emociones del espectador distorsionando y exagerando los temas.

4. Se basa en la intuición, depura, intensifica e interpreta la realidad, pero no se aparta totalmente de ella.

5. Utilizan colores fuertes y puros, formas retorcidas y una composición agresiva.

6. La luz y la perspectiva suele ser alterada.

7. Todas estas características se encuentran en muchos artistas que se adjuntan a esta corriente artística.

La obra La noche estrellada de Van Gogh, y Muerte en la habitación de la enfermera de Edvard Munch son claras muestras del arte expresionista. Podemos ver que Orozco tiene obras que muestran clara influencia de esta corriente, no solo es el caso de la obra Sacrificio Humano, también podemos identificar esta influencia en obras como Autorretrato y Teules IV. Este estilo pictórico también es recurrente en todas las obras pertenecientes a la exposición Los Teules de 1947.

\section{Exposición Los Teules 1947}

Antes de entrar de lleno en la obra Sacrificio Humano, es importante hablar de la exposición a la que esta obra pertenece. Durante el año de 1947 José Clemente Orozco inauguró la exposición Los Teules en El Colegio Nacional. Esta exposición estaba compuesta por 66 
obras, las cuales narran uno de los episodios históricos más importantes de México, la conquista. El autor tomó inspiración de la obra Historia verdadera de la conquista de la Nueva España de Bernal Díaz del Castillo, en la que se expresan crudas y violentas representaciones del encuentro entre indígenas y españoles (Museo de arte Carrillo Gil, 2017).

La exposición de Los Teules, "muestra una impactante reflexión sobre la conquista de México, cruda, sin concesiones, sin mitos fundadores, sin héroes ni vencedores; solo víctimas, la brutalidad espeluznante" (Museo de arte Carillo Gil, 2017: 20). A pesar de la crudeza de sus obras, la muestra tuvo un enorme éxito, y de acuerdo con las memorias del colegio, asistieron alrededor de 3,385 personas (Revista Escenarios, 2017). El Colegio Nacional fue creado por iniciativa del gobierno federal. Orozco ingresó como miembro fundador, en 1943, y se comprometió a presentar exposiciones anuales a cambio de la posibilidad de dar cátedra. "Así, el pintor entró a formar parte de una élite conformada por destacados intelectuales: historiadores, científicos, escritores y políticos, por lo que es probable que llamaran su atención algunos temas abordados por sus colegas" (Revista Escenarios, 2017:8).

El Colegio Nacional es una institución de rango cultural, científico, filosófico y literario, sus miembros fundadores fueron: el novelista Mariano Azuela; el arqueólogo Alfonso Caso; el filósofo Antonio Caso; el músico Carlos Chávez; los educadores José Vasconcelos, Ezequiel A. Chávez; el cardiólogo Ignacio Chávez; el poeta Enrique Gonzáles Martínez; el biólogo Isaac Ochoterena; el geólogo Ezequiel Ordóñez; los pintores José Clemente Orozco, Diego Rivera; el humanista Alfonso Reyes; el físico Manuel Sandoval Vallarta; y el oftalmólogo Manuel Uribe Troncoso (Secretaría de Cultura, 2014).

Durante su estancia en el Colegio Nacional, Orozco tuvo contacto con muchas obras. En aquel entonces, se publicaron varios libros de estudios biológicos sobre los órganos, y los avances de la cardiología, además de trabajos como el de Silvio Zavala sobre la historia del trabajo y la sociedad indígena en la Nueva España. Estos y más trabajos pudieron reconfigurar la noción que Orozco tenía sobre ciertos hechos. Con base en lo dicho por Cruz Porchini, Orozco

...hizo una desmitificación sobre la formar de contar la historia de la conquista, siempre hizo severas y liberales críticas a la concepción heroica de la resistencia indígena y cuestionó en buena medida la percepción académica (Revista Escenarios, 2017: 23).

Orozco evitó referirse a las contradicciones entre hispanidad (civilización) e indigenismo (barbarie), y se dedicó a mostrar llanamente, por medio de la pintura, el choque brutal entre las dos culturas. Pese a que con este conjunto, el artista quiso hacer una crítica del relato histórico, conservó cierta épica para representar escenas de guerra: heridos, cadáveres, fragmentos humanos, ríos de sangre y ritos ceremoniales. Con ello, Orozco privilegió la confrontación violenta entre españoles e indígenas, eliminando las figuras de códice, como él mismo las llamaba. La narración quiso ser semejante a las historias contadas en los murales: el momento previo al enfrentamiento, la lucha y las consecuencias (Revista Escenarios, 2017).

En esta serie de obras, Orozco revaloró muchos de los aspectos involucrados en la concepción del México antiguo, entre ellos, temas como los combates, matanzas, sacrificios, la noche triste. El nombre mismo de la exposición también tenía un significado en sí, "Los Teules era el calificativo usado por los indígenas para referirse a los conquistadores españoles, los cuales fueron confundidos con sus deidades" (Revista Escenarios, 2017: 23).

En sus diversas obras, Orozco reinterpretó la conquista y buscó representar la visión del pueblo mexica ante el conflicto. Desde mi punto de vista, Orozco no se muestra ni anti español, ni anti indígena, simplemente busca transmitir a los espectadores de su obra, el dolor humano, la crueldad, el miedo, el temor y la masacre, que se ve en todo conflicto militar. Según Mandel,

En contraste con la mirada idílica y utópica del mundo indígena ofrecida por Rivera, el enfoque de Orozco nos presenta la imagen de la guerra y del sacrificio humano: La mirada occidental sobre este mundo mítico y primitivo, más que civilizado, es lo que caracteriza la visión de Orozco sobre lo precolombino. Orozco vuelve a su pintura solo un medio para conocer este hecho histórico, y busca ser lo más objetivo posible con su narración gráfica (Mandel, 2007: 48).

Rivera enfatiza el pasado indígena como el auténtico paradigma de la identidad nacional, ya que representa, para el pintor, una época en la historia de México, en la que la Nación tenía la autonomía sufriente como para determinar su dirección fuera del alcance del dominio exterior. Para Rivera, entonces, el mundo precolombino es un fuerte símbolo nacionalista. En cambio, los paradigmas de Orozco fueron muy diferentes. Para él, las luchas y los acontecimientos históricos fueron parte de un solo conflicto, en donde las fuerzas del progreso competían con las fuerzas de la reacción en una secuencia circular, en la que ningún fragmento narrativo aislado podía ser dominante. Por ese motivo, Orozco rechazaba las composiciones utópicas, épicas y mitológicas, características de la producción de Diego Rivera (Mandel, 2007)

La exposición de Orozco se puede dividir en dos partes, por un lado, las obras con temas épicos, y por el otro, los dibujos como ejercicios compositivos. También se logra ver que, el aspecto anatómico de sus obras tiene una gran importancia, además otros elementos, como el cadáver, que toma gran relevancia. 
Ciertamente, dentro del lenguaje visual de los artistas del régimen posrevolucionario, había una obsesión sobre el cadáver. Para Orozco, posiblemente era un intento por contraponer el sacrificio humano -ilógico, cruel y trágico - con una modernidad científica, saludable y racional; estandarte de El Colegio Nacional. Por ejemplo, en pinturas como Sacrificio humano y Sin título exponen, de manera descarnada, el ritual prehispánico, pero al mismo tiempo, se refiere al conocimiento y a su interés por el estudio médico y la disección (Revista Escenarios, 2017).

En toda la serie de obras que componen esta exposición, Orozco muestra su gran calidad como pintor. Esto se logró no solo gracias a su gran experiencia, sino que también estudió minuciosamente la piroxilina y su aplicación para lograr efectos de calidad pictórica, sus pinceladas eran generalmente muy opacas, y a su vez, favoreció las texturas con insinuaciones casi abstractas (Revista Escenarios, 2017).

Mediante la serie de Los Teules, Orozco buscó reinterpretar el pasado indígena, y contar, de manera distinta, los relatos de la conquista.

Actualmente, la exposición de Los Teules ha sido retomada por el Museo de Arte Carrillo Gil (2017) y cuenta con 43 de las 66 piezas de la serie original de pinturas, dibujos y acuarelas.

\section{El sacrificio humano en la obra de Bernal Díaz del Castillo}

La obra Historia verdadera de la conquista de la Nueva España, escrita por Bernal Díaz del Castillo, fue la principal influencia para la exposición Los Teules. La obra de Díaz del Castillo ha sido, a través del tiempo, una de las más utilizadas, citadas y criticadas. En ella podemos encontrar la narración de la conquista vista desde la perspectiva de uno de sus soldados, este punto es de sumo interés, pues la visión de los españoles es totalmente distinta a la de los nativos. Además de que la obra Díaz del Castillo tiene un fin concreto, justificar la conquista.

Bernal Díaz comienza a redactar la "Historia verdadera", sobre la base de su relación de servicios y otros documentos generados alrededor del año 1541 (viaje a España). Además, Alonzo de Zorita menciona, en 1533, haber leído un borrador de dicha obra. Según testimonio del propio Díaz del Castillo, termina de trasladarla en 1568, pero no será publicada hasta 1632. Estas fechas permiten situar la obra en su época, la cual, como es bien conocido, está marcada por la polémica y la vitalidad critica. Los estudios dedicados a la problemática del discurso histórico y su situación en el siglo XVI, son numerosos (Rose De Fuggle, 2011). Por lo que cabe resaltar que, la obra de Díaz del Castillo no tiene un propósito documental sino más bien refutativo y persuasivo, en el cual el autor busca imponer una actitud ideológica (Rose de Fuggle, 2011). Su obra está formada en la mente europea, por tanto, la manera de describir todo lo que el autor percibe, se asemeja al mundo cultural europeo. Podríamos decir que la obra de Díaz del Castillo se sujeta a su tiempo y espacio, es por ello que tiene esta perspectiva del nuevo mundo.

La historia relatada por Bernal Díaz, no busca imponer una verdad absoluta sino más bien su versión de los hechos. Como escritor, tiene la necesidad de despertar y mantener el interés del lector, además de dar crédito a lo narrado y más aún, tiene que lograr convencer a sus lectores de que su narración es verdadera. Cabe resaltar que Bernal Díaz se enfrenta a un grave problema, pues debe relatar lo increíble a un público lejano y tener que lograr que éste le crea (Rose de Fuggle, 2011).

La obra tiene todo un discurso detrás, y el autor busca justificarla con una diversidad de técnicas de retórica y persuasión, él mismo busca legitimarse, primero que todo, se muestra como un elegido de Dios, pues al comenzar su texto, se encomienda a Dios y además, le agradece por haberle dado la oportunidad de redactar lo que atestigua. También, busca legitimarse a través de los hombres que le rodean, pues en su obra se la pasa elogiándoles, y diciendo que son hombres de calidad y que todos son hombres rectos. Asimismo, busca dar realce a su calidad moral, justificándose a través de otros, diciendo en sus textos, que hasta el mismo Cortés lo reconocía como un hombre valeroso (Rose de Fuggle, 2011).

Esto es solo un poco del discurso que está detrás de la obra de Bernal Díaz del Castillo. Reconociendo su estilo narrativo, su objetivo y sus sesgos podemos adentrarnos en su obra. Con base en ello, a continuación, analizaré algunos fragmentos de ésta, en donde se habla del sacrificio humano, aspecto que será crucial para la representación realizada por Orozco en su obra pictórica. En el texto de Díaz del Castillo hay muchas menciones de sacrificio, pero considero que hay algunas que son más relevantes que otras, pues en ellas, podemos identificar la perspectiva que tenían los conquistadores de este acto, además de lo aterrador que les parecía. Para comenzar, retomo el siguiente pasaje:

$Y$ desde que los caciques y papas de aquel pueblo y otros comarcanos vieron que tan justificados éramos y las palabras amorosas que Cortés les decía con nuestras lenguas, y también las cosas tocantes a nuestra santa fe, como lo teníamos de costumbre, y dejasen el sacrificio y de ser robar unos a otros y las suciedades de sodomías y que no adorasen sus malditos ídolos, y se les dijo otras muchas cosas buenas (Díaz del Castillo, 2012: 157).

En este fragmento podemos ver el claro repudio por el acto sacrificial, además de la visión cristiana que tenía Díaz del Castillo. Cabe resaltar que en otras partes del 
texto hay indicios de sacrificio, pues al pasar por algunas zonas, los conquistadores habían encontrado restos de personas sacrificadas.

Es en este fragmento, que se deja claro que los conquistadores querían acabar con la práctica de sacrificios, pues esto era un acto aborrecible para ellos, también enfatiza que querían que los indígenas dejasen de adorar a sus ídolos. Cabe destacar que lo que realmente buscaban los españoles era adueñarse de la tierra, puesto que a través de todo un discurso, buscan justificar la conquista. Para ello, recurren a un concepto medieval, la llamada "guerra justa", debido a que las creencias de los nativos se les tacha de idólatras, es así como se justifica el dominio hispano.

Otro ejemplo de ello es el siguiente fragmento:

$Y$ todos los caciques, papas y principales respondieron que no les estaba bien dejar sus ídolos y sacrificios, y que aquellos sus dioses les daban salud y buenas sementeras y todo lo que había menester; y que en cuanto a lo de las sodomías, que, por la resistencia en ello, para que no se use más (Díaz del Castillo, 2012: 159)

También, a su vez, podemos ver la respuesta de las propias indígenas, pues para ellos esto era común y gracias a ellos podían obtener muchas cosas, pues era la manera en que se comunicaban con sus dioses. Un pasaje aún más interesante es el siguiente, pues contiene una descripción de un sacrificio por extracción del corazón y del ritual conocido como antropofagia.

Y es desta manera: que ya me habrán oído decir que cuando sacrificaban algún triste indio, que le aserraban con unos navajones de pedernal por los pechos $y$, bulliendo, le sacaban el corazón y sangre y lo presentaban a sus ídolos, en cuyo nombre hacían aquel sacrificio y luego les cortaban los muslos y brazos y cabeza $Y$ aquello comían en fiestas y banquetes, y la cabeza colgaban de unas vigas; y el cuerpo del sacrificado no llegaban a él para le comer, sino dábanlo a aquellos bravos animales (Díaz del Castillo, 2012: 300).

La descripción dada en estas líneas es sumamente interesante, también podemos deducir que lo que se realiza es un sacrificio por extracción de corazón, pues no hay presencia de otros elementos que puedan dar indicio de otro acto ritual, puede ser que este fragmento haya sido la clara inspiración para la obra de Orozco.

Podemos notar que hay diversas menciones del sacrificio humano, y como hemos venido mencionando, esta obra fue fundamental para la exposición Los Teules, pues las menciones de sacrificio, guerra, desmembramientos, etcétera, son algunos de los tópicos en que se centra este conjunto de obras y que podemos claramente leer en la obra de Díaz del Castillo (ver imagen 1).
Figura 1. José Clemente Orozco, La trinchera (1926).

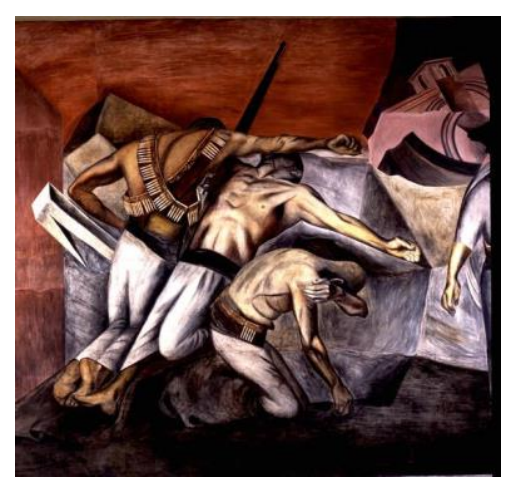

Fuente: Recuperada de https://bit.Iy/2BTM8UC

Hay un punto que a mi parecer es de vital interés, y sobre el cual no hay información, así que a partir de aquí lo que diré se basa en inferencias del autor de este texto. ¿Orozco llego a conocer la obra de alguno de los cronistas? Sin lugar a duda existen varias fuentes que nos han ayudado a conocer el pasado prehispánico de mejor manera, entre ellas destacan las crónicas de los diversos frailes que vinieron a México y los códices prehispánicos. Gracias a estas fuentes históricas podemos conocer muchísimo más del pasado indígena, actos como el sacrificio humano, los rituales, las fiestas, la cosmovisión.

Si bien no es posible saber si Orozco tuvo contacto o conocimiento de obras como las de fray Bernardino de Sahagún, fray Diego Durán, fray Bartolomé de las Casas, fray Toribio de Benavente (Motolinía) y fray Juan de Torquemada, me parece que son vitales para entender la obra de Orozco, pues en los escritos de los cronistas podemos encontrar narraciones de primera mano, de un espectador de un sacrificio humano. Por lo que esto nos ayudará a tener una mejor comprensión de la obra de Orozco, y contribuirá a entender lo representado en ella.

Asimismo, las representaciones de sacrificios en códices prehispánicos son muy comunes, por ello más adelante realizaré una comparación entre la representación de Orozco y la representación de un códice. Esto nos dará una mayor perspectiva del acto ritual, y a su vez, mostraré la precisión histórica de la obra de Orozco.

\section{El siglo $X X$}

Una de las mayores influencias en la obra pictórica de Orozco fue su contexto histórico, esto moldeó sus temáticas principales. En primera instancia, durante su participación en el movimiento muralista mexicano, el autor se tuvo que sujetarse a las ideas del movimiento, en donde predominaron temas como: La revolución, la lucha de clases y el hombre indígena. Fue en esta etapa donde Orozco realizó obras como: Omnisciencia, El hombre en llamas, Prometeo, Dartmouth, Miguel Hidalgo, 
Dioses del mundo moderno y Las soldaderas. Fueron solo algunas de las muchas obras que Orozco realizó en esta etapa.

En su trayectoria artística encontramos de manera recurrente varias obras que tienen como temática eje, la guerra. Estas obras no solo nos hablan de la guerra sino también de sus consecuencias, sus efectos, su crueldad, la crudeza y sus consecuencias. Todo esto lo podemos ver en obras como: La trinchera, Zapatistas, Katharsis, La destrucción del viejo orden, La despedida y La trinidad revolucionaria.

Todas estas obras fueron mero reflejo del conflicto armado mexicano, pero además de este conflicto, en el mundo de manera casi paralela se dio un conflicto mundial, la primera guerra mundial. Con esto en mente, podemos intuir que Orozco vivió una juventud en donde los conflictos armados marcaban un tópico en la sociedad. Históricamente el arte y la guerra han convivido; han existido grandes creaciones artísticas derivadas de los conflictos militares, ejemplos ello son: el Guernica de Pablo Picasso, Libertad Guiando al pueblo de Eugéne Delacroix o Wartime Moscow de Igor Pavlovich.

Éstas son solo algunas muestras de obras de arte que han buscado plasmar la visión de la guerra, desde el dolor, la batalla o los soldados. Desde que el hombre es hombre, la violencia se ha vuelto inspiración en variadas expresiones artísticas, se ha vuelto una emoción más, un testimonio visual del lado más salvaje del ser humano, la aniquilación de un ser humano por otro ser humano. (Eve Museos e Innovación, 2018).

En el año de 1936, se dio otro conflicto en el mundo, la guerra civil española, la cual propició que muchos españoles se refugiaran en México, entre ellos, grandes artistas. De nueva cuenta, la guerra estaba como un tema recurrente en la vida cotidiana, y que años más tarde, en 1939, se agudizara con el inicio de la segunda guerra mundial. El tema de la guerra estuvo presente en todo el mundo, pues la victoria del eje o los aliados, daría pie, principalmente, a un cambio mundial en cuanto a política, economía.

Al terminar la Segunda Guerra Mundial, justo dos años después, en 1947, Orozco creo la exposición Los Teules. Exposición que estuvo basada en una obra etnohistórica, que buscaba mostrar la otra cara de la conquista. $\mathrm{Si}$ analizamos la vida de Orozco, podemos ver que hubo un sinfín de conflictos militares que estuvieron presentes dentro de su sociedad formativa, lo que sin duda repercutió en su obra y se muestra de manera emblemática en esta exposición.

Sacrificio humano, la obra en que se centra este artículo, es no solo una representación de un acto ritual prehispánico, sino que a su vez, es una muestra de la brutalidad que se vivía en la sociedad mexica. Orozco busca mediante su pintura, que podamos observar el sacrificio humano y ser partícipes de él, ya que el autor nos encara y muestra lo que un ser humano puede hacer a otro, por su sistema de pensamiento. Los Teules es una exposición que posee un discurso detrás, en el que Orozco muestra lo brutal de la guerra, confronta al espectador, mostrándole que en su tiempo, a pesar de todos los avances tecnológicos y científicos, los hombres, nosotros, seguimos matándonos unos a otros, y la barbarie sigue a pesar de todo el avance que se ha dado.

\section{Análisis Sacrificio Humano}

La obra Sacrifico humano de José Clemente Orozco (imagen 2) fue realizada durante 1947, durante la tercera etapa del movimiento muralista, a su vez fue incluida en la exposición de Los Teules, la cual como ya he mencionado, son una serie de obras con una temática en común (la conquista). Asimismo, estas obras tienen como guía la obra Historia verdadera de la conquista de Nueva España de Bernal Díaz del Castillo.

\section{Figura 2. José Clemente Orozco, Sacrificio Humano (1947).}

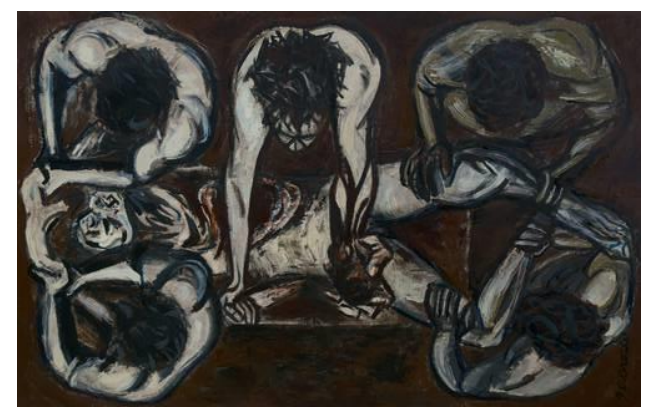

Fuente: Recuperada de https://cutt.ly/Fhm16wy

Como podemos observar, a primera vista, se identifican seis figuras humanas, mostradas desde una perspectiva cenital, que como lo dice el nombre de la obra, podemos ver un sacrificio humano. La figura central destaca por ser la persona sacrificada y justo en el centro superior, podemos ver a la persona que efectúa el sacrificio, es decir, el sacrificador.

La imagen cuenta con un total de seis figuras humanas, que, primero que nada, cabe resaltar que se encuentran realizando un sacrificio por extracción de corazón, y que explicadas representan: las cuatro personas de cada extremo son ayudantes del sacerdote principal (el cual se encuentra en el centro, sosteniendo el cuchillo de sacrificios). Según fray Diego Durán:

Además del sumo sacerdote, que era el que abría el pecho de la víctima y le extraía el corazón, una serie de personas colaboraban en todo el proceso. En primer lugar, cinco sacerdotes, también de alta jerarquía, que sostenían las piernas, brazos y cuello de la víctima en el momento del sacrificio y que recibían el nombre de Chachalmeca (Gómez, 1945: 31). 
Asimismo, podemos ver a los sacerdotes de color gris, con diversas variantes de acuerdo con la zona del cuerpo, esto debido a que según fray Diego Durán, los sacerdotes "se pintaban con hollín en algunas ceremonias" (Gómez, 1945:31). Sin duda una de las ceremonias más importantes era la del acto sacrificial, es por ello que vemos a los sacerdotes pintados.

En lo que respecta al entorno, podría deducirse que se está haciendo en un lugar cerrado, tal vez en un templo, pues en la obra no hay elementos que anclen a otro tipo de sitio. Cabe aclarar que no hay suficientes elementos para dar un enfoque único, pues al ver el acto sacrificial de manera cenital, solo podemos ver el piso de color café con algunas mezclas de color negro y rojo; el rojo es, a mi parecer, el color que más resalta y del cual podemos encontrar mayor nivel. Es claro que lo que representa es la sangre de la víctima. Si bien los actos sacrificiales eran rituales públicos, también había ocasiones en las que se hacían de manera más discretas.

Dentro de la obra, podemos apreciar una gran variedad de colores, desde gris, blanco, rojo, blanco, café, y negro. Todos estos tienen diversas tonalidades $\mathrm{e}$ intensidades, en general la paleta de colores, es fría. La luz en la obra es posible que sea natural, aunque esto no lo podemos afirmar, tal vez este efecto se deba a la perspectiva de la obra.

Finalmente, en lo que respecta a las texturas, son brumos o formas borrosas, este tipo de texturas permiten el juego de colores y luces, lo cual se ve claramente en la obra, sobre todo respecto a los colores. Cabe destacar la gran importancia de la luz y las texturas, pues pareciera ser que tienen una composición y ritmo casi simétrico.

El sacrificio humano era una práctica sumamente común en la región de Mesoamérica, pero debido a que Orozco, se basa en la obra de Historia verdadera de la conquista..., podemos concluir que lo que se representa es un sacrificio mexica. Es importante resaltar que dentro de un acto sacrificial había tres actores de suma importancia: el sacrificador, el sacrificante o sacrificantes y la víctima.

El sacrificador era la persona que trasladaba a la víctima a sacrificar, el sacrificante era la persona que daba muerte ritual a la víctima, regularmente eran sacerdotes o gobernantes, y la víctima era la persona que moría dentro de este acto ritual, por lo general eran cautivos de guerra o esclavos. (González, 1985) En la obra podemos ver representados a los sacrificantes y a la víctima.

El sacrificio por extracción del corazón se efectuaba de la siguiente manera: se colocaba a la víctima de espaldas sobre la piedra de sacrificios o téchcatl, de tal manera que le quedara el pecho tenso; cuatro sacerdotes le sostenían los pies y las manos, y un quinto, le colocaba una argolla de madera en la garganta para que no gritara. El sexto sacerdote, que era el principal, empuñaba un cuchillo de pedernal con ambas manos, y de un solo tajo le abría el pecho por debajo de las costillas o en el espacio intercostal, y por la herida, con una mano le arrancaba el corazón (Gómez, 1945).

Debido a lo mencionado, podemos identificar algunos elementos plasmados en la obra de Orozco. En su pintura se muestra a los cuatro sacerdotes que sostienen a la víctima, al sacerdote principal, así como a la víctima. También podemos ver otros elementos, como la argolla de manera, la daga de sacrificios, la piedra de sacrificios y el corazón de la víctima. Este último se encuentra siendo elevado a los cielos, para ser entregado a los dioses.

Continuando con los sacerdotes, el que se encuentra en el centro es el principal, pues es él quien realiza el sacrificio; los dos sacerdotes del lado izquierdo, se encuentran sosteniendo una collera, la cual se usaba para impedir que la víctima levantara la cabeza, se le colocaba en el cuello una especie de chincho, que jalaba hacia abajo uno de los cuatro sacerdotes. En la obra de Orozco podemos ver que acaba de ser retirada, pues el sacrificio ya fue efectuado.

El sacerdote principal sostiene un corazón y un cuchillo de pedernal, este cuchillo era el único permitido durante este acto ritual y recibía el nombre de técpatl. De acuerdo con Yolotl González Torres, este cuchillo estaba hecho de sílex o pedernal, que según, el fraile Motolinía especificaba:

Era una pieza de pedernal de aquellos con los que hacen lumbre, hecho con un hierro de lanza, no agudo mucho porque como es piedra recia y salta, no se puede parar aguda, esto digo porque muchos piensan que eran aquellas navajas de piedra negra que acá hay, que tienen el filo tan delgado como navajas de barbero (González, 1985: 176).

Además del técpatl, también podemos ver el corazón, el cual era concebido como el alimento de los dioses, ambos elementos se encuentran repletos de sangre. Justo en el centro de la obra podemos observar a la víctima del acto sacrificial y la piedra de sacrificios. Como ya se ha mencionado, la piedra de sacrificios era ocupada para llevar a cabo los sacrificios por extracción del corazón. La piedra se usaba para poder facilitar el acto sangriento, pues la víctima se recostaba sobre ella y facilitaba la labor de los sacerdotes (González, 1985).

Finalmente, la víctima "era el eje del rito sacrificial, al convertirse, con su muerte, en un ser de umbral que permitía la comunicación entre lo humano y lo sobrenatural" (González, 1985: 251). Este acto ritual era llevado a cabo en lo alto de los basamentos piramidales, pues "todos los sacrificios se efectuaban en lugares especiales que reunían el requisito básico de ser sagrados, característica que se adquiría porque en ellos se establecía la comunicación con la deidad" (González, 
1985: 153). Aunque este no es el caso, los sacrificios por extracción del corazón eran comúnmente practicados frente a un gran público, en la zona más alta de los basamentos piramidales, pero también eran practicados dentro de algún templo, es por ello que, dentro de la obra de Orozco, se muestra un lugar cerrado.

De acuerdo con lo presentado, la obra de Orozco, a mi parecer, no solo busca transmitir una práctica ritual sino que a su vez busca transmitir la brutalidad del acto y la visión que tuvieron los conquistadores del mismo, pues para ellos era un acto aborrecible, que era hecho para ídolos que nada tenían que ver con la fe católica. Desde mi punto de vista, Orozco busca transmitir la brutalidad de este acto, lo cual se puede percibir en varios puntos de su obra, una de ellas la paleta de colores, que sin duda destaca en su pintura.

Gracias a la perspectiva, el espectador puede ver todos los puntos importantes de la extracción del corazón, desde los diferentes sacerdotes sosteniendo a la víctima, hasta el sacerdote central sacando el corazón con las manos escurriendo sangre y alzándolo al cielo para ofrecerlo a los dioses.

Es pertinente comparar la obra de Orozco con la imagen del códice de Durán y ver las semejanzas en cuanto a representación de un sacrificio humano (ver figura 3 y 4).

Figura 3. Sacrificio por extracción de corazón.

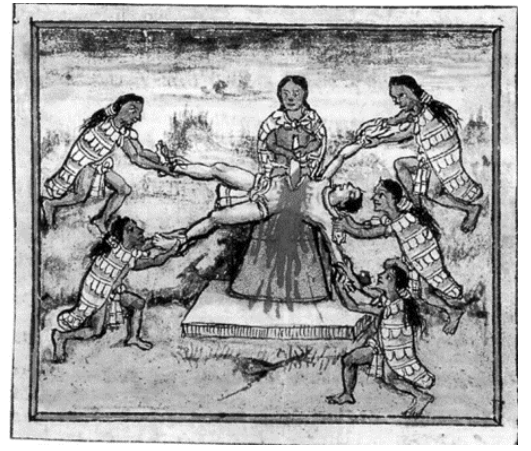

Fuente: Durán, 2005/1880, II: lámina 8.

Figura 4. José Clemente Orozco, Sacrificio Humano (1947).

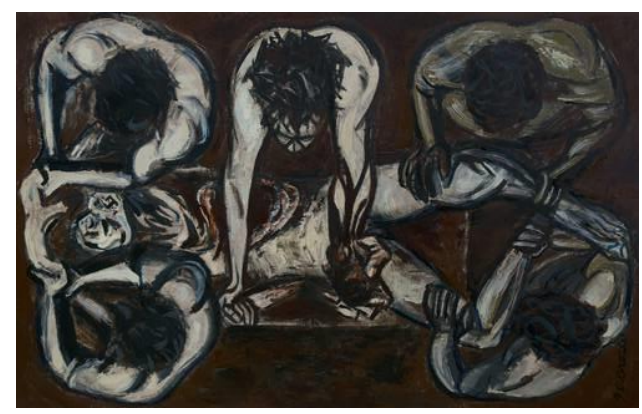

Fuente: Recuperada de https://cutt.ly/Fhm16wy
Podemos observar que ambas representaciones cuentan con los elementos principales de un sacrificio humano; en ambas vemos la ausencia del sacrificante, aludiendo a que éste es un sacrificio colectivo, y no solo eso, Orozco nos señala como participes del acto; de acuerdo con su obra, nosotros somos los sacrificantes. Se muestran estas dos obras, para subrayar la precisión del acto ritual representado por Orozco, el cual sin duda tiene rigor histórico.

\section{Consideraciones finales}

La obra de Orozco es sumamente importante, su exposición Los Teules da una gran visión de lo que fue la conquista de México. En la pintura Sacrificio Humano, podemos ver la visión que tenían los conquistadores de este acto, y el choque cultural. En la obra de Díaz del Castillo se ve reflejada la manera de entender y percibir el sacrificio humano, desde una cultura muy distinta a la mexica y esa extrañeza e incomprensión parece ser parte también de Los Teules.

La obra de Bernal Díaz del Castillo nos relata el acto sacrificial, como cruel y sangriento, que sin lugar a duda denota la clara influencia que tuvo en José Clemente Orozco. En su pintura los espectadores se vuelven uno con la obra. Los trazos del autor son agresivos, y los partícipes del acto quedan inmersos en total anonimato. Incluso podemos ver el dolor que sufrió la víctima, si bien se busca el anonimato en la obra, la figura del sacrificado destaca por estar sumamente destrozada.

En mi opinión, Orozco busca compartir el dolor de aquel muerto; podemos ver la abertura en el pecho por donde el sacerdote principal sacó el corazón y cómo, a su vez, este lo sostiene en lo alto. Tanto el corazón como el técpatl están envueltos en sangre. Este es un acto simbólico de entrega y devoción hacia la deidad a la que fue ofrecido el sacrificio.

También podemos ver que la piedra de sacrificios está llena de sangre, es decir, no es la primera víctima que ha sido sacrificada en ella; en el piso incluso vemos más sangre, muestra de que no fue el primer sacrificio, ha habido muchos.

Orozco busca transmitir con esta obra lo doloroso que era morir de esta manera, busca transmitir el dolor de la muerte y la crueldad de estos actos. Asimismo, con su obra busca reconfigurar la idea que se tenía sobre la conquista. Es decir, no ver a los conquistadores como unos monstruos que buscaban acabar con los indígenas, o ver a los indígenas como los vencidos o como la gran cultura que todo lo dominaba, sino más bien, el discurso de la obra es la crueldad de la muerte, lo fatídico que es morir de esta manera, lo doloroso, incluso hasta lo triste. La exposición de Los Teules es una crítica directa a los actos bélicos que azotaron la época en la que vivió el autor. Esta exposición no solo busca mostrar parte del 
pasado histórico de México sino que busca criticar el presente. La exposición explora todo lo que trae consigo la guerra y quiere que el espectador pueda verlo y entenderlo.

Finalmente, es importante señalar que la exposición de Los Teules es una crítica a la actualidad, pues los conflictos armados solo traen desgracia, pobreza, y muerte. En la obra Sacrificio humano, Orozco nos confronta; en su pintura, somos nosotros los que presenciamos el acto sacrificial y a su vez, somos quienes lo permitimos. El autor cuestiona a los espectadores, pues aún en pleno siglo XX, las personas se siguen matando unas a otras, por no congeniar con sus ideas o visión del mundo. En la guerra no hay buenos ni malos, solo personas combatiendo $y$ matándose las unas a las otras, por su manera de entender y percibir la realidad.

\section{Referencias}

Consejo alemán de Arte (1967). El Arte Del Expresionismo alemán gráfica plástica. Una exposición. Goethe--Instituí.

Delgadillo, Marco Antonio y Rico, Alfredo (2008). "El muralismo mexicano, el arte al servicio de la nación". La Gaceta UDG, 28 de julio, 2008, p. 6 [En línea]. México, disponible en: http://148.202.105.20/dgmgac/Hemeroteca/paginas/537/G537_cot\%20 $\underline{6 . p d f}$

Díaz del Castillo, Bernal. (2012). "Historia verdadera de la conquista de la Nueva España” [En línea]. Disponible en: https://www.rae.es/sites/default/files/Aparato de variantes_Historia_v erdadera de la conquista de la Nueva Espana.pdf $[10$ de enero de 2020]

Durán, Diego (2005). "Historia de las indias de la Nueva España y islas de la tierra firme". Obra original 1880, México, ed. Ignacio Escalante [En línea] disponible en: http://www.cervantesvirtual.com/obra/historia-delas-indias-de-nueva-espana-y-islas-de-tierra-firme-tomo-ii--0/ $[2 \mathrm{de}$ junio de 2020]

Eve Museos e Innovación (2018). "El Arte y la Guerra" en Eve Museos e Innovación Exposiciones. Disponible en: https://evemuseografia.com/2014/01/04/el-arte-y-la-guerra/ $\left[\begin{array}{ll}20 & \text { de }\end{array}\right.$ febrero de 2020]

Garrido, Esperanza (2009). "La pintura mural mexicana, su filosofía e intención didáctica" en: Sophía, Colección de Filosofía de la Educación [En Línea] No.1, Cuenca Ecuador: Universidad Politécnica Salesiana. Disponible en: https://sophia.ups.edu.ec/index.php/sophia/article/view/6.2009.03 [20 de febrero de 2020]

Gómez, Federico (1945). Costumbres de Nueva España «Costumbres, fiestas, enterramientos y diversas formas de proceder de los indios de Nueva España»(Vol. II). México: Tlalocan.

González Torres, Yolotl (1985). El sacrificio humano entre los mexicas. Ciudad de México, México: Fondo de Cultura Económica.

Lucie-Smith, Edward (1993). Arte Latinoamericano del siglo XX [En Línea] Barcelona, España: Ediciones Destino. Disponible en: https://catalog.library.vanderbilt.edu/discovery/fulldisplay/alma991036 931579703276/01VAN_INST:vanui [20 de febrero de 2020]

Mandel, Claudia (2007). "Muralismo mexicano: arte público/identidad/memoria colectiva". Escena Revista de las artes [En Línea]. 30(61), pp. 37-54. Disponible en: $\underline{\text { https://revistas.ucr.ac.cr/index.php/escena/article/view/8181 }}\left[\begin{array}{ll}21 & \text { de }\end{array}\right.$ febrero de 2020]

Museo de Arte Carrillo Gil (2017). "Orozco y los Teules, 1947 [Recopilación de análisis de las obras pertenecientes a la colección Los Teules de José Clemente Orozco]". [En Línea]. México:
https://www.academia.edu/34974701/Orozco_y_Los Teules_DCP_pd f [22 de febrero de 2020]

Museo del Palacio de Bellas Artes (2016). "Muralistas" [En línea]. México, disponible

en: https://documentosjalar.wordpress.com/2016/11/08/muralismomexicano/ [2 de marzo de 2020]

Ocampo, Javier (2005). "José Vasconcelos y la Educación Mexicana". Revista Historia de la Educación Latinoamericana, pp. 139-159. disponible en: https://www.redalyc.org/pdf/869/86900707.pdf $[26 \mathrm{de}$ marzo de 2020]

Revista Escenarios (2017). "Entrevista con Dafne Cruz Porchini, curadora de la exposición Orozco y Los Teules, 1947" [En línea]. México, disponible en: https://www.youtube.com/watch?v=-QZCMwPSOZc [10 de marzo de 2020]

Rose de Fuggle, Sonia (2011) "El narrador fidedigno: problemas de autoacreditación en la obra de Bernal Díaz del Castillo". Literatura Mexicana, pp. 327-349. Disponible en https://revistasfilologicas.unam.mx/literaturamexicana/index.php/lm/article/view/806 [26 de marzo de 2020]

Secretaría de Cultura (2014). "Cumple el Colegio Nacional 70 años de enriquecer la cultura de México", disponible en: https://www.gob.mx/cultura/prensa/cumple-el-colegio-nacional-70anos-de-enriquecer-la-cultura-de-mexico [11 de marzo de 2020] 